\title{
Assisted sonocatalytic degradation of pethidine hydrochloride (dolantin) with some inorganic oxidants caused by CdS-coated $\mathrm{ZrO}_{2}$ composite
}

\author{
Yingying Huang a , Hongbo Zhang a , Chunsheng Wei ${ }^{\text {a,b }}$, Guanshu Li ${ }^{\text {c }}$, Qiong Wu ${ }^{\text {a }}$, Jun \\ Wang $^{\text {a,c, } * \text {, Youtao Song }}{ }^{\mathrm{c}, *}$ \\ ${ }^{a}$ College of Chemistry, Liaoning University, Shenyang 110036, P. R. China \\ ${ }^{\mathrm{b}}$ National Police University of China, Shenyang 110854, P. R. China \\ ${ }^{c}$ College of Environment, Liaoning University, Shenyang 110036, P. R. China
}

Received 00 January 2016; received in revised form 00 January 2016; accepted 00 January 2016;

Available online 00 January 2016

A B S T R A C T

CdS was synthesized via hydrothermal method and $\mathrm{CdS}$-coated $\mathrm{ZrO}_{2}$ composite was prepared via chemica

precipitation method. And then they were characterized by X-ray diffractometer (XRD), scanning electron microscopy (SEM), transmission electron microscopy (TEM) and X-ray photoelectron spectroscopy (XPS). After that, the sonocatalytic degradation of pethidine hydrochloride (dolantin) in aqueous solution was conducted adopting CdS-coated $\mathrm{ZrO}_{2}$ composite as sonocatalyst with inorganic oxidant assisted. In addition, some influencing factors such as inorganic oxidant kind, including persulfate $\left(\mathrm{K}_{2} \mathrm{~S}_{2} \mathrm{O}_{8}\right)$, perchlorate $\left(\mathrm{NaClO}_{4}\right)$ and periodate $\left(\mathrm{KIO}_{4}\right)$, inorganic oxidant concentration and ultrasonic irradiation time on sonocatalytic degradation of pethidine hydrochloride were examined by using gas chromatograph. The experimental results showed that the used inorganic oxidants can effectively assisted the sonocatalytic degradation of pethidine hydrochloride caused by CdS-coated $\mathrm{ZrO}_{2}$ composite and the increase effects arrange as the order of $\mathrm{K}_{2} \mathrm{~S}_{2} \mathrm{O}_{8}>$ $\mathrm{KIO}_{4}>\mathrm{NaClO}_{4}$. And the best sonocatalytic degradation ratio $(95.50 \%)$ of pethidine hydrochloride could be obtained when the conditions of $10.00 \mathrm{mmol} / \mathrm{L} \mathrm{K}_{2} \mathrm{~S}_{2} \mathrm{O}_{8}, 1.00 \mathrm{~g} / \mathrm{L}$ prepared CdS-coated $\mathrm{ZrO}_{2}$ composite, $135 \mathrm{~min}$

\footnotetext{
* Corresponding author. Tel.: +86-24-62207861; fax: +86-24-62202053.

E-mail address: wangjun888tg@126.com (J. Wang); wangjun891@sina.com (J. Wang).

0000-0000/\$ - see front matter ( 2016 Elsevier Ltd. All rights reserved. http://dx.doi.org/00.0000/j.seppur.2016.00.000
} 
ultrasonic irradiation (40 kHz frequency and $300 \mathrm{~W}$ output power), $100 \mathrm{~mL}$ total volume and $25-28{ }^{\circ} \mathrm{C}$ temperature were adopted. However, only using $\mathrm{CdS}$-coated $\mathrm{ZrO}_{2}$ as sonocatalyst without any inorganic oxidants merely reaches $20 \%$ degradation ratio of pethidine hydrochloride when other conditions are the same. The method of sonocatalytic degradation assisted with inorganic oxidants may be an efficient sonocatalytic system for degradation of pethidine hydrochloride.

(C) 2016 Elsevier B.V. All rights reserved.

Keywords: sonocatalyst; CdS-coated $\mathrm{ZrO}_{2}$ composite; inorganic oxidant; assisted sonocatalytic degradation; pethidine hydrochloride (dolantin). 


\section{Assisted sonocatalytic degradation of pethidine hydrochloride (dolantin) with some inorganic oxidants caused by CdS-coated $\mathrm{ZrO}_{2}$ composite}

Yingying Huang a , Hongbo Zhang a , Chunsheng Wei ${ }^{\text {a,b }}$, Guanshu Li ${ }^{\mathrm{c}}$, Qiong Wu ${ }^{\text {a }}$, Jun Wang ${ }^{\text {a,c, } * \text {, Youtao Song }}{ }^{\mathrm{c}, *}$

${ }^{a}$ College of Chemistry, Liaoning University, Shenyang 110036, P. R. China

${ }^{\mathrm{b}}$ National Police University of China, Shenyang 110854, P. R. China

${ }^{c}$ College of Environment, Liaoning University, Shenyang 110036, P. R. China

\section{A R T I C L E I N FO}

Article history:

Received 00 January 2016

Revised 00 January 2016

Accepted 00 January 2016

Available online 00 January 2016

Keywords:

Sonocatalyst

CdS-coated $\mathrm{ZrO}_{2}$ composite

inorganic oxidant

assisted sonocatalytic degradation

pethidine hydrochloride (dolantin)

\section{A B S T R A C T}

\footnotetext{
* Corresponding author. Tel.: +86-24-62207861; fax: +86-24-62202053.

E-mail address: wangjun888tg@126.com (J. Wang); wangjun891@ sina.com (J. Wang).

0000-0000/\$ - see front matter @ 2016 Elsevier Ltd. All rights reserved.

http://dx.doi.org/00.0000/j.seppur.2016.00.000
} 
CdS was synthesized via hydrothermal method and $\mathrm{CdS}$-coated $\mathrm{ZrO}_{2}$ composite was prepared via chemical precipitation method. And then they were characterized by X-ray diffractometer (XRD), scanning electron microscopy (SEM), transmission electron microscopy (TEM) and X-ray photoelectron spectroscopy (XPS). After that, the sonocatalytic degradation of pethidine hydrochloride (dolantin) in aqueous solution was conducted adopting $\mathrm{CdS}$-coated $\mathrm{ZrO}_{2}$ composite as sonocatalyst with inorganic oxidant assisted. In addition, some influencing factors such as inorganic oxidant kind, including persulfate $\left(\mathrm{K}_{2} \mathrm{~S}_{2} \mathrm{O}_{8}\right)$, perchlorate $\left(\mathrm{NaClO}_{4}\right)$ and periodate $\left(\mathrm{KIO}_{4}\right)$, inorganic oxidant concentration and ultrasonic irradiation time on sonocatalytic degradation of pethidine hydrochloride were examined by using gas chromatograph. The experimental results showed that the used inorganic oxidants can effectively assisted the sonocatalytic degradation of pethidine hydrochloride caused by CdS-coated $\mathrm{ZrO}_{2}$ composite and the increase effects arrange as the order of $\mathrm{K}_{2} \mathrm{~S}_{2} \mathrm{O}_{8}>$ $\mathrm{KIO}_{4}>\mathrm{NaClO}_{4}$. And the best sonocatalytic degradation ratio $(95.50 \%)$ of pethidine hydrochloride could be obtained when the conditions of $10.00 \mathrm{mmol} / \mathrm{L} \mathrm{K}_{2} \mathrm{~S}_{2} \mathrm{O}_{8}, 1.00 \mathrm{~g} / \mathrm{L}$ prepared CdS-coated $\mathrm{ZrO}_{2}$ composite, $135 \mathrm{~min}$ ultrasonic irradiation (40 kHz frequency and $300 \mathrm{~W}$ output power), $100 \mathrm{~mL}$ total volume and $25-28{ }^{\circ} \mathrm{C}$ temperature were adopted. However, only using CdS-coated $\mathrm{ZrO}_{2}$ as sonocatalyst without any inorganic oxidants merely reaches $20 \%$ degradation ratio of pethidine hydrochloride when other conditions are the same. The method of sonocatalytic degradation assisted with inorganic oxidants may be an efficient sonocatalytic system for degradation of pethidine hydrochloride.

(C) 2016 Elsevier B.V. All rights reserved.

\section{Introduction}

Narcotic drugs abuse may do harm to people's health by making person produce the physical and mental dependence [1]. What is worse, it makes families into economic bankruptcy even leads to the harrowing break-up. Pethidine hydrochloride (dolantin) is a phenylpiperidine derivative, which is firstly synthetic analgesic drug to achieve the wide therapeutic use [2,3]. Acting as an opiate agonist, pethidine hydrochloride has the similar pharmacological effect with morphine [4]. Long-term abuse and accidental ingestion will result in dependence and damage of central nervous system (CNS), even 
lead to death $[5,6]$. On a global scale, many pharmaceutical factories in the production of pethidine hydrochloride would discharge waste water containing pethidine hydrochloride into our environment

On the other hand, every year some hospitals would also produce a lot of out-of-date pethidine hydrochloride. What's more, public security organ could seize a large number of pethidine hydrochloride every year. So the harmless treatment of pethidine hydrochloride is a major problem that we must face to. In the past, there were some methods to dispose pethidine hydrochloride, such as incineration, landfill, adsorption and so on [8]. Nevertheless, these methods are generally incomplete and insecure, even ofen bring secondary pollution. Therefore, it is indispensable to seek a better way to dispose pethidine hydrochloride. Perhaps, for a special biological active substance breaking its molecular structure and chemical composition to reach the harmlessness may be feasible.

The sonocatalytic technology combining with semiconductors has been received much attention in solving environmental problems [9-12]. Because of many advantages, such as strong penetrability, special transmission mode, high efficiency and simple operation, therefore, it can become an effective way to decompose the organic dyes in non- or low-transparent effluents [13-15]. Perhaps, this way should also be feasible to dispose narcotic drugs. In the past, sonocatalytic degradation of many organic pollutants employing titanium dioxide $\left(\mathrm{TiO}_{2}\right)$ powder as sonocatalyst has been reported [16-19]. The bandwidth of $\mathrm{TiO}_{2}$ is $3.2 \mathrm{eV}$, and its valence band (VB) and conduction band (VB) electric potentials are $2.91 \mathrm{eV}$ and $-0.29 \mathrm{eV}$ [20], respectively. For most of organic pollutants, $\mathrm{TiO}_{2}$ is enough to effectively decompose them through photocatalytic or sonocatalytic reaction process Nevertheless, narcotic drugs are some stable substances chemically. Apparently, in order to destroy narcotic drugs, it is necessary to select some of broadband semiconductor oxides as sonocatalysts. Due to the bandwidth of $5.0 \mathrm{eV}$ and relatively low $\mathrm{VB}$ electric potential of $3.91 \mathrm{eV}$, 
$\mathrm{ZrO}_{2}$ should have much stronger oxidation capacity under ultrasonic irradiation [23-25]. However, because of such wide bandwidth of $\mathrm{ZrO}_{2}$, only a small portion of ultraviolet light in sonoluminescence can be used [26-28]. In order to broaden the response range towards light and avoid the recombination of electron $\left(\mathrm{e}^{-}\right)$-hole $\left(\mathrm{h}^{+}\right)$pairs, using a narrowband semiconductor to combine with $\mathrm{ZrO}_{2}$ may be feasible [29-33]. CdS has bandwidth of $2.42 \mathrm{eV}$ and is an applicable semiconductor. Being similar to photocatalytic reaction, such combination will enhance the sonocatalytic activity of $\mathrm{ZrO}_{2}$ [34-37].

In this paper, the nano-sized CdS was synthesized via hydrothermal method and the CdS-coated $\mathrm{ZrO}_{2}$ composite was prepared via chemical precipitation method. And then the CdS-coated $\mathrm{ZrO}_{2}$ composite was chosen as sonocatalyst to carry out sonocatalytic degradatyion of pethidine hydrochloride. In addition, it has been reported that the addition of inorganic oxidants could further enhance the sonocatalytic degradation efficiency of pollutants [38-41]. Therefore, in this study, some inorganic oxidants were used to assist sonocatalytic degradation. Through the reaction of inorganic oxidants with the electrons on the conduction band (CB) of $\mathrm{ZrO}_{2}$, the reactive oxygen species (ROS) oxidants can be generated. The influences of inorganic oxidant kind and concentration as well as ultrasonic irradiation time on the sonocatalytic degradation of pethidine hydrochloride were studied. The degradation process and corresponding mechanism were tentatively proposed. It is wished that the sonocatalytic degradation method assisted with inorganic oxidants can be used to treat the narcotic drugs in aqueous solution.

\section{Experimental}

\subsection{Materials and reagents}

Cadmium chloride $\left(\mathrm{CdCl}_{2} \cdot 2.5 \mathrm{H}_{2} \mathrm{O}\right)$ and sodium sulphide nonahydrate $\left(\mathrm{Na}_{2} \mathrm{~S} \cdot 9 \mathrm{H}_{2} \mathrm{O}\right)$ (Sinopharm 
Chemical Regent Co, Ltd, China) were used to prepare the nano-sized cadmium sulphide (CdS). Zirconium oxychloride $\left(\mathrm{ZrOCl}_{2} \cdot 8 \mathrm{H}_{2} \mathrm{O}\right)$ and ammonium hydroxide (Sinopharm Chemical Regent Co, Ltd, China) were used to prepare the nano-sized $\mathrm{ZrO}_{2}$. Pethidine hydrochloride $(99.99 \%$ purity, Tianjin Kaiyuan Reagent Corporation, China) was used to undergo the sonocatalytic degradation. Potassium persulfate $\left(\mathrm{K}_{2} \mathrm{~S}_{2} \mathrm{O}_{8}\right)$, sodium perchlorate $\left(\mathrm{NaClO}_{4} \cdot \mathrm{H}_{2} \mathrm{O}\right)$ and potassium periodate $\left(\mathrm{KIO}_{4}\right)$ (AR, Tianjin Kemiou chemicals Corporation, China) were purchased as assisted inorganic oxidants. Lidocaine (Sigma-Aldrich, MO, USA) was used as internal standard. All the reagents were of analytical purity grade, and were directly used without further purification.

X-ray powder diffractometer (XRD, D-8, Bruker-axs, Germany, Ni filtered Cu Ka radiation in the range of $2 \theta$ from $10^{\circ}$ to $70^{\circ}$ ), transmission electron microscopy (TEM, JEOL JEM2100, Hitachi Corporation, Japan) and scanning electron microscopy (SEM, JEOL JSM-5610LV, Hitachi Corporation, Japan) were used to determine the crystalline phase. X-ray photoelectron spectroscopy (XPS, Escalab 250XI, Thermo, America) was used to determine the element type and composition content of CdS-coated $\mathrm{ZrO}_{2}$ composite. Gas chromatograph Agilent 6890 (Agilent technologies, Massy, France) was used to inspect the sonocatalytic degradation ratio of pethidine hydrochloride in aqueous solution. Controllable Serial-Ultrasonics apparatus (KQ-300, Kunshan Company, China) was adopted to irradiate the pethidine hydrochloride aqueous solution, operating at ultrasonic frequency of $40 \mathrm{kHz}$ and output power of $300 \mathrm{~W}$ through manual adjust. Apparatus of ultrasonic irradiation has been shown in our past work $[42,43]$.

\subsection{Preparation of nano-sized CdS powder}

Nano-sized CdS particles were prepared by using a hydrothermal method. $6.0 \mathrm{mmol}$ of $\mathrm{CdCl}_{2} \cdot 2.5$ 
$\mathrm{H}_{2} \mathrm{O}$ was dissolved in $40 \mathrm{~mL}$ distilled water, then $6.0 \mathrm{mmol}$ sodium sulphide $\mathrm{Na}_{2} \mathrm{~S}$ solution was added with continuous stirring for $30 \mathrm{~min}$. Subsequently, the solution was transferred into a $50 \mathrm{~mL}$ polytetrafluoro-ethylene (PTFE) autoclave equipped with a stainless steel shell and maintained at $100{ }^{\circ} \mathrm{C}$ for $4.0 \mathrm{~h}$. After cooling to room temperature, the orange precipitation was collected through filter and washed several times alternately with ethanol and distilled water, and then vacuum-dried at $80{ }^{\circ} \mathrm{C} 3.0 \mathrm{~h}$ followed by calcination in air for $3.0 \mathrm{~h}$ at $500{ }^{\circ} \mathrm{C}$ and grinded for the following experiments and characterizations.

\subsection{Preparation of sonocatalysts $\mathrm{CdS}$-coated $\mathrm{ZrO}_{2}$ composite}

$\mathrm{ZrO}_{2}$ prepared by chemical precipitation method $5.80 \mathrm{mmol}(1.8691 \mathrm{~g})$ of zirconium oxychloride $\mathrm{ZrOCl}_{2} \cdot 8 \mathrm{H}_{2} \mathrm{O}$ was dissolved in $50 \mathrm{~mL}$ of deionised water and precipitated the hydroxides with an aqueous solution of $6.0 \% \mathrm{NH}_{3}$ at $\mathrm{pH} 9.9$ and stirred vigorously. The precipitate was filtered and washed to make it free from chloride ion and ammonia, and then dissolved in a small amount of water. After that $1.90 \mathrm{mmol}(0.2810) \mathrm{g}$ of nano-sized CdS powder was added to the above solution with stirring vigorously. Then filtered and washed with distilled water. The washed product was dried at $120{ }^{\circ} \mathrm{C}$ in air for $12 \mathrm{~h}$ followed by calcination in air for $3.0 \mathrm{~h}$ at $350{ }^{\circ} \mathrm{C}$. After fully grinding, the CdS-coated $\mathrm{ZrO}_{2}$ composite was obtained.

\subsection{Characterization of the prepared $\mathrm{CdS}$-coated $\mathrm{ZrO}_{2}$ composite}

The prepared CdS-coated $\mathrm{ZrO}_{2}$ composite particles as sonocatalysts were characterized by X-ray powder diffractometer (XRD, D-8, Bruker-axs, Germany, Ni filtered $\mathrm{Cu} K \alpha$ radiation in the range of $2 \theta$ from $10^{\circ}$ to $70^{\circ}$ ), scanning electron microscopy (SEM, JEOL JSM-5610LV, Hitachi Corporation, Japan), transmission electron microscopy (TEM, JEOL JEM2100, Hitachi Corporation, Japan) and 
X-ray photoelectron spectroscopy (XPS, Escalab 250XI, Thermo, America).

\subsection{Measurements of sonocatalytic activity of the prepared $\mathrm{CdS}$-coated $\mathrm{ZrO}_{2}$ composite}

Sonocatalytic degradation experiments of pethidine hydrochloride were carried out in a $150 \mathrm{~mL}$ erlenmeyer flask placed in an ultrasonic irradiation apparatus $(300$ (length) $\times 180 \mathrm{~mm}$ (width) $\times 120$ mm (height), KQ-300, 40 kHz, 300 W, six transducers, Kunshan ultrasonic apparatus Company, China) under air atmosphere. In the common experiment, $1.00 \mathrm{~g} / \mathrm{L}$ CdS-coated $\mathrm{ZrO}_{2}$ composite, $2.70 \mathrm{~g} / \mathrm{L}$ (10.00 mmol/L) $\mathrm{K}_{2} \mathrm{~S}_{2} \mathrm{O}_{8}, 2.30 \mathrm{~g} / \mathrm{L}(10.00 \mathrm{mmol} / \mathrm{L}) \mathrm{KIO}_{4}, 1.23 \mathrm{~g} / \mathrm{L}(10.00 \mathrm{mmol} / \mathrm{L}) \mathrm{NaClO}_{4}$ and 10.00 $\mathrm{mg} / \mathrm{L}$ pethidine hydrochloride concentration in $100 \mathrm{~mL}$ total volume were adopted to perform the sonocatalytic degradation. Before ultrasonic irradiation, the above solutions were stirred for $30 \mathrm{~min}$ in the dark to achieve adsorption-desorption equilibrium. And then, the degradation of pethidine hydrochloride was performed under ultrasonic irradiation for $160 \mathrm{~min}$. At $45 \mathrm{~min}$ interval, from the degradation liquid a certain of sample was removed and measured by gas chromatograph. The degradation ratios of pethidine hydrochloride were determined from the peak area ratio change of pethidine hydrochloride solution using the following equation:

Degradation ratio $(\%)=\left[\mathrm{A}_{\mathrm{o}} / \mathrm{A}_{\mathrm{s}}-\mathrm{A}_{\mathrm{t}} / \mathrm{A}_{\mathrm{s}}\right] /\left(\mathrm{A}_{\mathrm{o}} / \mathrm{A}_{\mathrm{s}}\right) \times 100$

Where $A_{o}$ is the initial peak area of pethidine hydrochloride solution, $A_{t}$ is the instant peak area after a certain of ultrasonic irradiation time $(\mathrm{t})$ and $\mathrm{A}_{\mathrm{s}}$ is the peak area of internal standard.

In addition, the influences of inorganic oxidant kind and concentration on sonocatalytic degradation of pethidine hydrochloride were also investigated in detail.

\section{Results and discussion}




\subsection{XRD patterns of the prepared $\mathrm{CdS}$-coated $\mathrm{ZrO}_{2}$ composite}

The XRD patterns of prepared nano-sized CdS powder (a), nano-sized $\mathrm{ZrO}_{2}$ powder (b) and CdS-coated $\mathrm{ZrO}_{2}$ composite (c) were given in Fig. 1. As can be seen in Fig. 1(a), the XRD pattern of $\mathrm{CdS}$ shows some sharp narrow peaks at $2 \theta=24.7^{\circ}(100), 26.5^{\circ}(002), 28.3^{\circ}(101), 36.6^{\circ}(102), 43.8^{\circ}$ (110), $48.1^{\circ}(103)$ and $51.8^{\circ}(112)$, which are almost same as the JCPDS card 41-1049 of hexagonal wurtzite phase of CdS [45]. In Fig. 1(b), it can be seen that the diffraction signals at $2 \theta=23.98^{\circ}(110)$. $28.08^{\circ}(11 \overline{1}), 31.32^{\circ}(111), 34.64^{\circ}(002)$ and $50.7^{\circ}(220)$ are related to the monoclinic $\mathrm{ZrO}_{2}$ phase as the JCPDS card 83-0944. From Fig. 1(c) it can be found that the XRD pattern shows clearly the peaks corresponding to hexagonal $\mathrm{CdS}$ and monoclinic $\mathrm{ZrO}_{2}$, which indicates that the $\mathrm{CdS}$ and $\mathrm{ZrO}_{2}$ have been successfully composited together to form the CdS-coated $\mathrm{ZrO}_{2}$ composite.

\section{Fig. 1.}

\subsection{SEM and TEM images of the prepared $\mathrm{CdS}$-coated $\mathrm{ZrO}_{2}$ composite}

In this section, the SEM images of nano-sized CdS, nano-sized $\mathrm{ZrO}_{2}$ and composite are depicted in Fig. 2(a-c), respectively. It can be seen that in Fig. 2(a) there are a lot of homogenous and spherical crystal particles with diameters in the range of 40-60 nm, which should pertain to the typical crystal form of nano-sized CdS particles. Fig. 2(b) shows that the nano-sized $\mathrm{ZrO}_{2}$ particles aggregated into compact irregular shapes with diameters in the range of 50-70 nm. And the SEM image of Fig. 2(c) demonstrates that $\mathrm{ZrO}_{2}$ and $\mathrm{CdS}$ have been combined to form a coated (core-shell) structure, and the $\mathrm{ZrO}_{2}$ are uniformly coated on the surface of nano-sized CdS particles, which leaded to an enlargement of the nanoparticle size. The diameters of CdS-coated $\mathrm{ZrO}_{2}$ are in the 
with $\mathrm{ZrO}_{2}$ films.

\section{Fig. 2.}

Fig. 2(d) shows the TEM image of the CdS-coated $\mathrm{ZrO}_{2}$ composite particles. It can be seen that the nano-sized CdS particles displays the slightly regular shape with the average diameter about $50 \mathrm{~nm}$. Besides, the $\mathrm{ZrO}_{2}$ is uniformly dispersed on the surface of nano-sized $\mathrm{CdS}$ particles. Furthermore, the TEM results confirm that the CdS-coated $\mathrm{ZrO}_{2}$ composites form a coated (core-shell) structure with the diameters of $150 \mathrm{~nm}$.

\subsection{XPS spectra of the prepared $\mathrm{CdS}$-coated $\mathrm{ZrO}_{2}$ composite}

X-ray photoelectron spectroscopy (XPS) is one of the most effective and most widely used analytical techniques in the surface analysis. In this section, it was mainly used to analysize the element and valence of the prepared CdS-coated $\mathrm{ZrO}_{2}$ composite and the obtained results are given in Fig. 3. Thereinto, Fig. 3(o) shows the fully XPS scanned spectra of the prepared CdS-coated $\mathrm{ZrO}_{2}$ composite. As shown in Fig. 3(o), the strong peaks of $\mathrm{Cd}, \mathrm{S}, \mathrm{Zr}$ and $\mathrm{O}$ elements appear and the corresponding peaks are plotted carefully, which indicates that these elements compose the prepared CdS-coated $\mathrm{ZrO}_{2}$ composite. Specifically, it can be seen that in Fig. 3(a) the peak of O (1s) is at 532.1 $\mathrm{eV}$. There is only one peak of $\mathrm{O}$ atom, which indicates that it is the $\mathrm{O}$ atom combined with $\mathrm{Zr}$ atom forming $\mathrm{ZrO}_{2}$ rather than $\mathrm{CdO}$. In Fig. 3(b), for $\mathrm{Zr}$ (3d) there are two peaks at 182.3 and $184.6 \mathrm{eV}$, which belongs to $\mathrm{Zr}\left(3 \mathrm{~d}_{5 / 2}\right)$ and $\mathrm{Zr}\left(3 \mathrm{~d}_{3 / 2}\right)$, respectively. These are consistent with that reported in literature [47]. From Fig. 3(c and d), the peaks at 406.63, 410.6 and $162.76 \mathrm{eV}$ belong to the binding energies of $\mathrm{Cd}\left(3 \mathrm{~d}_{5 / 2}\right), \mathrm{Cd}\left(3 \mathrm{~d}_{3 / 2}\right)$ and $\mathrm{S}\left(2 \mathrm{p}_{3 / 2}\right)$, respectively. More specifically, EDX analysis reveals that the percent content of the elements (PP At. \%) are Cd: $8.52 \%, \mathrm{~S}: 10.91 \%, \mathrm{Zr}: 20.57 \%$ and O: 
$46.13 \%$. It indicated that the chemical composition of the prepared CdS-coated $\mathrm{ZrO}_{2}$ sample is very close to the calculated values of CdS-coated $\mathrm{ZrO}_{2}$. And these results are consistent with the XRD pattern presented above as well.

\section{Fig. 3.}

\subsection{Gas chromatography of pethidine hydrochloride solutions during sonocatalytic degradation}

Gas chromatography is a beneficial tool in the study on degradation process of narcotic drug as well as in the calculation of degradation ratio. The gas chromatograms of pethidine hydrochloride solution $(10.00 \mathrm{mg} / \mathrm{L})$ under $135 \mathrm{~min}$ ultrasonic irradiation in the presence of different kinds of inorganic oxidants $(10 \mathrm{mmol} / \mathrm{L})$ are given in Fig. 4 . It can be seen that there are two peaks for original solution. One peak appears approximately at Rt (retention time) $=4.87 \mathrm{~min}$, which should be the adsorption peak of pethidine hydrochloride. And the other one peak at $\mathrm{Rt}=5.63 \mathrm{~min}$ belong to the lidocaine internal standard. There are no interfering peaks at the retention times of pethidine hydrochloride and the internal standard. Also, there is no carryover problem (memory effect) in this experiment. When the prepared CdS-coated $\mathrm{ZrO}_{2}$ composite was adopted as sonocatalyst without any inorganic oxidants, the peak of pethidine hydrochloride reduced to a certain extent, which showed that only the presence of prepared $\mathrm{CdS}$-coated $\mathrm{ZrO}_{2}$ composite would degrade pethidine hydrochloride to some degree, but it is a little inconspicuously. When adding different inorganic oxidants, compared with original solution, it can be seen that the absorption peaks of pethidine hydrochloride all give an apparent decrease, and the reduced order is original solution $<\mathrm{US} / \mathrm{CdS}$-coated $\mathrm{ZrO}_{2}<\mathrm{US} / \mathrm{CdS}$-coated $\mathrm{ZrO}_{2} / \mathrm{NaClO}_{4}<\mathrm{US} / \mathrm{CdS}$-coated $\mathrm{ZrO}_{2} / \mathrm{KIO}_{4}<\mathrm{US} / \mathrm{CdS}$-coated $\mathrm{ZrO} / \mathrm{K}_{2} \mathrm{~S}_{2} \mathrm{O}_{8}$. Especially, when the 
$\mathrm{K}_{2} \mathrm{~S}_{2} \mathrm{O}_{8}$ was used to assist CdS-coated $\mathrm{ZrO}_{2}$ under ultrasonic irradiation, the peak of pethidine hydrochloride declined drastically and that nearly disappeared. It showed that the pethidine hydrochloride in aqueous solution was almost degraded completely. It also indicates that the prepared CdS-coated $\mathrm{ZrO}_{2}$ composite as a sonocatalyst assisted with inorganic oxidant can effectively degradate pethidine hydrochloride.

\section{Fig. 4.}

\subsection{Influence of inorganic oxidant kind and concentration on sonocatalytic degradation}

In order to find out the effects of inorganic oxidant kind and concentration on the sonocatalytic degradation of pethidine hydrochloride, a series of experiments were carried out within the range $(0.00-15.00 \mathrm{mmol} / \mathrm{L})$ of inorganic oxidant concentration at $5.00 \mathrm{mmol} / \mathrm{L}$ intervals for three kinds of inorganic oxidant $\left(\mathrm{K}_{2} \mathrm{~S}_{2} \mathrm{O}_{8}, \mathrm{KIO}_{4}\right.$ and $\left.\mathrm{NaClO}_{4}\right)$. The amount of the prepared CdS-coated $\mathrm{ZrO}_{2}$ composite was fixed as $1.00 \mathrm{~g} / \mathrm{L}$ and the obtained results are presented in Fig. 5. First, it can be seen that, for these three systems, US/CdS-coated $\mathrm{ZrO}_{2} / \mathrm{K}_{2} \mathrm{~S}_{2} \mathrm{O}_{8}$, US/CdS-coated $\mathrm{ZrO}_{2} / \mathrm{KIO}_{4}$ and US/CdS-coated $\mathrm{ZrO}_{2} / \mathrm{NaClO}_{4}$, the similar change trend appears. That is, the sonocatalytic degradation ratios of pethidine hydrochloride in the presence of $1.00 \mathrm{~g} / \mathrm{L}$ prepared $\mathrm{CdS}$-coated $\mathrm{ZrO}_{2}$ composite within 135 min of ultrasonic irradiation all ascend gradually with the rises of inorganic oxidant concentration from $0.00 \mathrm{mmol} / \mathrm{L}$ to $10.00 \mathrm{mmol} / \mathrm{L}$ for $\mathrm{K}_{2} \mathrm{~S}_{2} \mathrm{O}_{8}, \mathrm{KIO}_{4}$ and $\mathrm{NaClO}_{4}$. And then, they slightly decrease with the further rises of inorganic oxidant concentration from $10.00 \mathrm{mmol} / \mathrm{L}$ to 15.00 $\mathrm{mmol} / \mathrm{L}$. It indicates that for these three systems the addition of inorganic oxidants apparently enhances the ability of sonocatalytic degradation indeed. However, too much inorganic oxidants may change the surface property of $\mathrm{CdS}$-coated $\mathrm{ZrO}_{2}$ composite particles, which is likely to decrease the 
sonocatalytic activity.

Moreover, at any concentration of inorganic oxidants the sonocatalytic degradation ratios of pethidine hydrochloride keep a settled order all along, namely, US/CdS-coated $\mathrm{ZrO}_{2} / \mathrm{NaClO}_{4}<$ US/CdS-coated $\mathrm{ZrO}_{2} / \mathrm{KIO}_{4}<\mathrm{US} / \mathrm{CdS}$-coated $\mathrm{ZrO}_{2} / \mathrm{K}_{2} \mathrm{~S}_{2} \mathrm{O}_{8}$. It indicates that the adding proper concentration of $\mathrm{K}_{2} \mathrm{~S}_{2} \mathrm{O}_{8}$ (about $10.00 \mathrm{mmol} / \mathrm{L}$ ) can obviously assist the sonocatalytic degradation of pethidine hydrochloride $(10.00 \mathrm{mg} / \mathrm{L})$ in aqueous solution. Of course, a much higher concentration of inorganic oxidants probably results in generating the excessive $\cdot \mathrm{OH}$ radicals instantaneously. These excessive $\cdot \mathrm{OH}$ radicals would maybe recombine, and then form less reactive $\mathrm{H}_{2} \mathrm{O}_{2}$ molecules, which leads to a slight decrease the sonocatalytic degradation ratio of pethidine hydrochloride. In addition, utilizing of a higher concentration of inorganic oxidants is likely to give rise to the adsorption of anion species on the surface of CdS-coated $\mathrm{ZrO}_{2}$ composite particles, which prevents the degradation reaction on the surface of sonocatalyst [48].

Above all, the highest degradation ratio was attained in the presence of prepared composite assisted with $10.00 \mathrm{mmol} / \mathrm{L}$ inorganic oxidants including $\mathrm{NaClO}_{4}, \mathrm{KIO}_{4}$ and $\mathrm{K}_{2} \mathrm{~S}_{2} \mathrm{O}_{8}$, and the corresponding relative sonocatalytic degradation ratio was $36.90 \%, 48.90 \%$ and $95.50 \%$, respectively. The results demonstrated that the combination of CdS-coated $\mathrm{ZrO}_{2}$ composite and inorganic oxidants was more efficient to decompose the pethidine hydrochloride than CdS-coated $\mathrm{ZrO}_{2}$ sonocatalyst individual, which may be due to the synergistic influence of various highly reactive radicals generated. And the positive influence of inorganic oxidants assisted sonocatalytic degradation of pethidine hydrochloride caused by CdS-coated $\mathrm{ZrO}_{2}$ composite was found to be in the order of $\mathrm{K}_{2} \mathrm{~S}_{2} \mathrm{O}_{8}>\mathrm{KIO}_{4}>\mathrm{NaClO}_{4}$. 


\section{Fig. 5.}

\subsection{Influence of ultrasonic irradiation time and corresponding reaction kinetics on}

sonocatalytic degradation of pethidine hydrochloride

The comparison of sonocatalytic degradation ratios of pethidine hydrochloride at different ultrasonic irradiation time was carried out for six systems (US/CdS-coated $\mathrm{ZrO}_{2}$, US/CdS-coated $\mathrm{ZrO}_{2} / \mathrm{NaClO}_{4}$, US/CdS-coated $\mathrm{ZrO}_{2} / \mathrm{KIO}_{4}$, US/CdS-coated $\mathrm{ZrO}_{2} / \mathrm{K}_{2} \mathrm{~S}_{2} \mathrm{O}_{8}, \mathrm{US} / \mathrm{ZrO}_{2}$ and US) and the corresponding results were given in Fig. 6. It can be observed from Fig. 6(a) that, on the one hand, all sonocatalytic degradation ratios of pethidine hydrochloride in these six systems increase with the increase of ultrasonic irradiation time. And the sequence based on the sonocatalytic degradation ratios is essentially $\mathrm{US}<\mathrm{US} / \mathrm{ZrO}_{2}<\mathrm{US} / \mathrm{CdS}$-coated $\mathrm{ZrO}_{2}<\mathrm{US} / \mathrm{CdS}$-coated $\mathrm{ZrO}_{2} / \mathrm{NaClO}_{4}<\mathrm{US} / \mathrm{CdS}$-coated $\mathrm{ZrO}_{2} / \mathrm{KIO}_{4}<\mathrm{US} / \mathrm{CdS}$-coated $\mathrm{ZrO}_{2} / \mathrm{K}_{2} \mathrm{~S}_{2} \mathrm{O}_{8}$. Apparently, the sonocatalytic degradation ratio in the presence of CdS-coated $\mathrm{ZrO}_{2}$ composite assisted with $\mathrm{K}_{2} \mathrm{~S}_{2} \mathrm{O}_{8}$ increases much faster with the increase of ultrasonic irradiation time than other five systems under the same conditions. On the other hand, within 180 min ultrasonic irradiation, the sonocatalytic degradation ratios reached $11.00 \%, 16.40 \%$, $22.20 \%, 37.40 \%, 46.40 \%$ and $89.70 \%$, respectively, for US, US/ZrO $2, \mathrm{US} / \mathrm{CdS}$-coated $\mathrm{ZrO}_{2}$, US/CdS-coated $\quad \mathrm{ZrO}_{2} / \mathrm{NaClO}_{4}$, US/CdS-coated $\quad \mathrm{ZrO}_{2} / \mathrm{KIO}_{4}$ and US/CdS-coated $\quad \mathrm{ZrO}_{2} / \mathrm{K}_{2} \mathrm{~S}_{2} \mathrm{O}_{8}$.

Therefore, a conclusion was drawn that some inorganic oxidants can efficiently assist the sonocatalytic degradation of pethidine hydrochloride in the presence of CdS-coated $\mathrm{ZrO}_{2}$ composite. It can be speculated further that most of the pethidine hydrochloride molecules could be soon degraded completely in the US/CdS-coated $\mathrm{ZrO}_{2} / \mathrm{K}_{2} \mathrm{~S}_{2} \mathrm{O}_{8}$ system.

\section{Fig. 6.}


In addition, in order to infer the sonocatalytic degradation rates of pethidine hydrochloride for these four systems, the reaction kinetics were studied. Here, the data of $-\ln \left(\mathrm{C}_{t} / \mathrm{C}_{0}\right)$ for first-order reaction as a function of ultrasonic irradiation time (t) was calculated [49]. In fact, as shown in Fig. 6(b), the results indicate that all calculated values of $-\ln \left(\mathrm{C}_{\mathrm{t}} / \mathrm{C}_{0}\right)$ are approximately linear with the ultrasonic irradiation time (t) all through. That is, the sonocatalytic degradation processes of pethidine hydrochloride for these six systems are all conformed to be pseudo first-order kinetics reactions. The kinetic equations corresponding to US, US/ZrO 2 , US/CdS-coated $\mathrm{ZrO}_{2}$, US/CdS-coated $\mathrm{ZrO}_{2} / \mathrm{NaClO}_{4}$, US/CdS-coated $\mathrm{ZrO}_{2} / \mathrm{KIO}_{4}$ and US/CdS-coated $\mathrm{ZrO}_{2} / \mathrm{K}_{2} \mathrm{~S}_{2} \mathrm{O}_{8}$ are $-\ln \left(\mathrm{C}_{\mathrm{t}} / \mathrm{C}_{0}\right)=0.0005 \mathrm{t}+0.004\left(\mathrm{R}^{2}\right.$ $=0.9926),-\ln \left(C_{t} / C_{0}\right)=0.0011 t+0.012\left(R^{2}=0.9778\right),-\ln \left(C_{t} / C_{0}\right)=0.0013 t+0.0458\left(R^{2}=0.8608\right)$, $-\ln \left(\mathrm{C}_{\mathrm{t}} / \mathrm{C}_{0}\right)=0.0026 \mathrm{t}+0.077\left(\mathrm{R}^{2}=0.8828\right),-\ln \left(\mathrm{C}_{\mathrm{t}} / \mathrm{C}_{0}\right)=0.0034 \mathrm{t}+0.108\left(\mathrm{R}^{2}=0.8724\right)$ and $-\ln \left(\mathrm{C}_{\mathrm{t}} / \mathrm{C}_{0}\right)=$ $0.0119 t+0.4426\left(\mathrm{R}^{2}=0.8449\right)$, respectively. The rate constants are $0.0005 \mathrm{~min}^{-1}, 0.0011 \mathrm{~min}^{-1}$, $0.0013 \mathrm{~min}^{-1}, 0.0026 \mathrm{~min}^{-1}, 0.0034 \mathrm{~min}^{-1}$ and $0.0119 \mathrm{~min}^{-1}$, respectively. Thus, the order of sonocatalytic degradation rates for these six systems can be judged as $\mathrm{US}<\mathrm{US} / \mathrm{ZrO}_{2}<$ US/CdS-coated $\mathrm{ZrO}_{2}<$ US/CdS-coated $\mathrm{ZrO}_{2} / \mathrm{NaClO}_{4}<\mathrm{US} / \mathrm{CdS}$-coated $\mathrm{ZrO}_{2} / \mathrm{KIO}_{4}<\mathrm{US} / \mathrm{CdS}$-coated $\mathrm{ZrO}_{2} / \mathrm{K}_{2} \mathrm{~S}_{2} \mathrm{O}_{8}$.

\subsection{Possible mechanism and process on sonocatalytic degradation assisted with inorganic} oxidants

In general, under ultrasonic irradiation, the micro-bubbles in liquid form, vibrate, grow and aggregate acoustic energy, finally formed cavitation bubbles fast collapse in almost adiabatic process accompanied by the generation of localized high temperatures and high pressures. It is called as ultrasonic cavitation effect [19]. It is known that the sonoluminescence caused by ultrasonic cavitation 
could produce the light with a wide wavelength range. The bandwidth of $\mathrm{ZrO}_{2}$ as a wide-band conductor material is about $5.0 \mathrm{eV}$. And the bandwidth of $\mathrm{CdS}$ as a narrow-band conductor material is about $2.4 \mathrm{eV}$. The prepared $\mathrm{CdS}$-coated $\mathrm{ZrO}_{2}$ composite with core-shell structure should have wide light response range due to the combination of wide-band and narrow-band conductor materials. That is, the ultraviolet light is able to excite $\mathrm{ZrO}_{2}$, and the visible light can excite $\mathrm{CdS}$ [50]. Since the research on the sonocatalytic degradation of pethidine hydrochloride has not been much yet, the corresponding mechanism can only be tentatively proposed as shown in Fig. 8. It can be considered that the long wavelength (visible) light with low energy from sonoluminescence penetrates $\mathrm{ZrO}_{2}$ shell of CdS-coated $\mathrm{ZrO}_{2}$ composite and then excites internal nano-sized CdS particles, so as a result the electron-hole pairs are generated. In the CdS, these photogenerated electrons from valence band (VB) get transferred to conduction band (CB). At the same time, the short wavelength (ultraviolet) light with high energy also from sonoluminescence is absorbed by $\mathrm{ZrO}_{2}$ and excites $\mathrm{ZrO}_{2}$ directly. Similarly, in the $\mathrm{ZrO}_{2}$ the photogenerated electrons from valence band (VB) of get transferred to conduction band (CB). The electrons on the conduction band (CB) of $\mathrm{ZrO}_{2}$ can be quickly consumed because of their strong reaction activity. And then the electrons on the conduction band (CB) of internal $\mathrm{CdS}$ cores transfer to the conduction band (CB) of $\mathrm{ZrO}_{2}$ shell.

In CdS-coated $\mathrm{ZrO}_{2}$ composite, the $\mathrm{CdS}$ core lies in the center of core-shell structure. As narrow-band conductor materials the $\mathrm{CdS}$ can continuously generate electrons and holes on the conduction band (CB) and valence band (VB), respectively, under visible light irradiation. Although these generated electrons and holes can not directly take part in any chemical reaction, they continually enter the conduction band (CB) and valence band (VB) of external $\mathrm{ZrO}_{2}$ shell, respectively. Moreover, the generated holes can directly degrade the pethidine hydrochloride absorbed on the 
surface of CdS-coated $\mathrm{ZrO}_{2}$ composite particles. Also, they can oxidize the water molecules $\left(\mathrm{H}_{2} \mathrm{O}\right)$ to produce the hydroxyl radicals $(\bullet \mathrm{OH})$, indirectly destroying the pethidine hydrochloride in aqueous solution. At the same time, the photogenerated electrons react with the molecular oxygen $\left(\mathrm{O}_{2}\right)$ dissolved in aqueous solution and then produce the superoxygen radical anions $\left(\cdot \mathrm{O}_{2}{ }^{-}\right)$. After a series of chemical reactions these superoxygen radical anions $\left(\cdot \mathrm{O}_{2}{ }^{-}\right)$can also become the hydroxyl radicals $(\bullet \mathrm{OH})$ with strong oxidation capacity [42]. These hydroxyl radicals $(\bullet \mathrm{OH})$ can also degrade the surrounding pethidine hydrochloride, leading to volatile degradation by-products or $\mathrm{CO}_{2}, \mathrm{H}_{2} \mathrm{O}$ and mineral acids through entire mineralization. The possible process is thought as following:

$$
\begin{aligned}
& {\left[\mathrm{CdS} \text {-coated } \mathrm{ZrO}_{2}\right]+\text { light or heat } \rightarrow\left[\text { CdS-coated } \mathrm{ZrO}_{2}\right]^{*}} \\
& {\left[\mathrm{CdS} \text {-coated } \mathrm{ZrO}_{2}\right]^{*} \rightarrow\left[\text { CdS-coated } \mathrm{ZrO}_{2}\right]+\mathrm{h}^{+}+\mathrm{e}^{-}} \\
& \mathrm{H}_{2} \mathrm{O}+\mathrm{h}^{+} \rightarrow \cdot \mathrm{OH}+\mathrm{H}^{+} \\
& \mathrm{O}_{2}+\mathrm{e}^{-} \rightarrow \cdot \mathrm{O}_{2}^{-} \\
& \cdot \mathrm{O}_{2}^{-}+\mathrm{H}^{+} \rightarrow \mathrm{HO}_{2} \\
& \mathrm{HO}_{2}+\mathrm{H}_{2} \mathrm{O} \rightarrow \mathrm{H}_{2} \mathrm{O}_{2}+\cdot \mathrm{OH} \\
& \mathrm{H}_{2} \mathrm{O}_{2}+\text { light or heat } \rightarrow 2 \cdot \mathrm{OH} \\
& \text { pethidine hydrochloride }+\cdot \mathrm{OH} \rightarrow \mathrm{D}^{+} \rightarrow \mathrm{D}^{++} \rightarrow \rightarrow \mathrm{CO}_{2}+\mathrm{H}_{2} \mathrm{O}+\mathrm{NO}_{3}^{-}
\end{aligned}
$$

The valence band (VB) of $\mathrm{ZrO}_{2}$ has a relatively more positive potential. The produced holes can directly degrade the pethidine hydrochloride due to its strong oxidation ability. In order to further promote the oxidation reaction on the pethidine hydrochloride, the produced electrons on the conduction band $(\mathrm{CB})$ can interact with various inorganic oxidants under ultrasonic irradiation and generate a large numbers of ROS oxidants. These generated ROS oxidants can also participate in the degradation of pethidine hydrochloride by radical oxidation pathways to assist the sonocatalytic 
degradation. The detailed process may be as following

$$
\begin{aligned}
& \mathrm{S}_{2} \mathrm{O}_{8}^{2-}+\mathrm{e}^{-} \rightarrow \cdot \mathrm{SO}_{4}{ }^{-}+\mathrm{SO}_{4}{ }^{2-} \\
& \mathrm{SO}_{4}^{-}+\mathrm{H}_{2} \mathrm{O} \rightarrow \mathrm{H}_{2} \mathrm{SO}_{4}+\mathrm{O}^{-} \\
& \mathrm{O}^{-}+\mathrm{H}^{+} \rightarrow \cdot \mathrm{OH} \\
& \mathrm{ClO}_{4}^{-}+\mathrm{e}^{-} \rightarrow \mathrm{ClO}_{3}^{-}+\mathrm{O}^{-} \\
& \mathrm{O}^{-}+\mathrm{H}^{+} \rightarrow \cdot \mathrm{OH}^{-} \\
& \mathrm{IO}_{4}^{-}+\mathrm{e}^{-} \rightarrow \mathrm{IO}_{3}^{-}+\mathrm{O}^{-} \\
& \mathrm{O}^{-}+\mathrm{H}^{+} \rightarrow \cdot \mathrm{OH}
\end{aligned}
$$

pethidine hydrochloride $+\cdot \mathrm{OH} \rightarrow \mathrm{D}^{+} \rightarrow \mathrm{D}^{++} \rightarrow \rightarrow \mathrm{CO}_{2}+\mathrm{H}_{2} \mathrm{O}+\mathrm{NO}_{3}^{-}$

\section{Fig. 7.}

\section{Conclusions}

In this work, via hydrothermal method and chemical precipitation method the CdS-coated $\mathrm{ZrO}_{2}$ composite as sonocatalyst was prepared and then characterized by X-ray diffractometer (XRD), scanning electron microscopy (SEM), transmission electron microscopy (TEM) and X-ray photoelectron spectroscopy (XPS). Adopting CdS-coated $\mathrm{ZrO}_{2}$ composite as sonocatalyst, the sonocatalytic degradation of pethidine hydrochloride in aqueous solution could be carried out. Particularly, some inorganic oxidants can effectively assist the sonocatalytic degradation of pethidine hydrochloride in the presence of $\mathrm{CdS}$-coated $\mathrm{ZrO}_{2}$ composite. The sonocatalytic degradation of pethidine hydrochloride is related with inorganic oxidant kind and the increase effects arrange as the order of $\mathrm{K}_{2} \mathrm{~S}_{2} \mathrm{O}_{8}>\mathrm{KIO}_{4}>\mathrm{NaClO}_{4}$. In addition, the sonocatalytic degradation ratio of pethidine hydrochloride increases with increasing inorganic oxidant concentration and ultrasonic irradiation time. 
The best sonocatalytic degradation ratio $(95.50 \%)$ of pethidine hydrochloride could be obtained when the conditions of $10.00 \mathrm{mmol} / \mathrm{L} \mathrm{K}_{2} \mathrm{~S}_{2} \mathrm{O}_{8}, 1.00 \mathrm{~g} / \mathrm{L}$ prepared CdS-coated $\mathrm{ZrO}_{2}$ composite, $135 \mathrm{~min}$ ultrasonic irradiation (40 kHz frequency and $300 \mathrm{~W}$ output power), $100 \mathrm{~mL}$ total volume and $25-28{ }^{\circ} \mathrm{C}$ temperature were adopted. It can be forecasted that the method of sonocatalytic degradation assisted with inorganic oxidants is an efficient sonocatalytic system for degradation of pethidine hydrochloride.

\section{Acknowledgements}

The authors greatly acknowledge the National Science Foundation of China (21371084), Key Laboratory Basic Research Foundation of Liaoning Provincial Education Department (L2015043), Liaoning Provincial Department of Education Innovation Team Projects (LT2015012) and Youth Science Foundation of Liaoning University (2013LDQN14) for financial support. The authors also thank our colleagues and other students for their participating in this work.

\section{References}

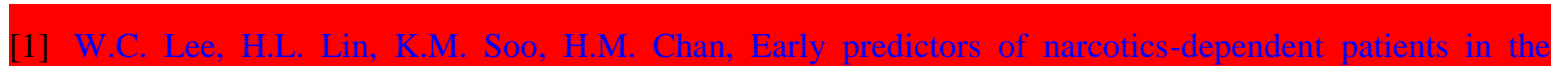

emergency department, Kaohsiung. J. Med. Sci. 29 (2013) 319-324

[2] A. Farina, G. Gostoli, E. Bossu, A. Montinaro, C. Lestingi, R. Lecce, LC-MS determination of MPTP a

sub-ppm level in pethidine hydrochloride, J. Pharmaceut. Biomed 37 (2005) 1089-1093.

[3] A.E.H. Elbohoty, H.A. Elrazek, M.A.E. Gawad, K.H.I. Abd-El-Maeboud, Intravenous infusion of

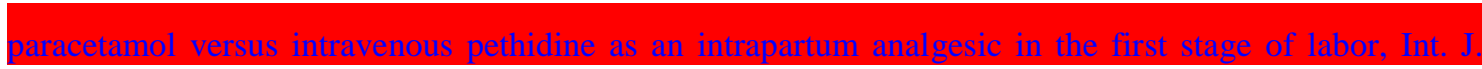

Gynaecol. Obstet. 118 (2012) 7-10.

[4] D. Szkutnik, S. Dyderski, K. Majcher, Determination of pethidine in rabbit plasma by capillary gas chromatography, Eur. J. Pharm. Sci. 14 (2001) 317-321.

[5] B.J. Wang, G.H. Zhang, X. Wu, G.Y. Hu, B.L. Zhu, Pethidine-induced neuronal apoptosis in rat brain, 
6] Y.A. Tamimi, K.F. Ilett, M.J. Paech, Estimation of infant dose and exposure to pethidine and norpethidine via breast milk following patient-controlled epidural pethidine for analgesia post caesarean delivery, Int. J. Obstet Anesth. 20 (2011) 128-134.

[7] B.Y. Han, Y. Du, E.K. Wang, Simultaneous determination of pethidine and methadone by capillary lectrophoresis with electrochemiluminescence detection of tris(2,2'-bipyridyl)ruthenium(II), Microchem. J. 89 (2008) 137-141.

[8] C.Y. Fu, X.L. Tang, Q. Yang, Q. Chen, R. Wang, Effects of rat/mouse hemokinin-1, a mammalian achykinin peptide, on the antinociceptive activity of pethidine administered at the peripheral and supraspinal level, Behav. Brain. Res. 184 (2007) 39-46.

[9] J. Wang, Y.F. Jiang, Z.H. Zhang, G. Zhao, G. Zhang, T. Ma, W. Sun, Investigation on the sonocatalytic degradation of congo red catalyzed by nanometer rutile $\mathrm{TiO}_{2}$ powder and various influencing factors, Desalination 216 (2007) 196-208.

[10] J. Wang, Z.J. Pan, Z.H. Zhang, X.D. Zhang, F.Y. Wen, T. Ma, Y.F. Jiang, L. Wang, L. Xu, P.L. Kang, Sonocatalytic degradation of methyl parathion in the presence of nanometer and ordinary anatase titanium dioxide catalysts and comparison of their sonocatalytic abilities, Ultrason. Sonochem. 13 (2006) 493-500.

[11] J.K. Im, J. Yoon, N. Her, J. Han, K.D. Zoh, Y. Yoon, Sonocatalytic-TiO ${ }_{2}$ nanotube, Fenton, and $\mathrm{CCl}_{4}$ reactions for enhanced oxidation, and their applications to acetaminophen and naproxen degradation, Sep. Purif. Technol. 141 (2015) 1-9.

[12] M.T. Taghizadeh, P.S. Aghjekohal, Sonocatalytic degradation of 2-hydroxyethyl cellulose in the presence of some nanoparticles, Ultrason. Sonochem. 26 (2015) 265-272.

[13] L.N. Yin, J.Q. Gao, J. Wang, B.X. Wang, R.Z. Jiang, K. Li, Y. Li, X.D. Zhang, Enhancement of sonocatalytic performance of $\mathrm{TiO}_{2}$ by coating $\mathrm{Er}^{3+}: \mathrm{YAlO}_{3}$ in azo dye degradation, Sep. Purif. Technol. 81 (2011) 94-100.

[14] L.M. Song, C. Chen, S.J. Zhang, Q.W. Wei, Sonocatalytic degradation of amaranth catalyzed by La ${ }^{3+}$ doped $\mathrm{TiO}_{2}$ under ultrasonic irradiation, Ultrason. Sonochem. 18 (2011) 1057-1061.

[15] J.Q. Gao, R.Z. Jiang, J. Wang, P.L. Kang, B.X. Wang, Y. Li, K. Li, X.D. Zhang, The investigation of sonocatalytic activity of $\mathrm{Er}^{3+}: \mathrm{YAlO}_{3} / \mathrm{TiO}_{2}-\mathrm{ZnO}$ composite in azo dyes degradation, Ultrason. Sonochem. 18 (2011) 541-548. 
[16] J. Wang, Y.H. Lv, Z.H. Zhang, Y.Q. Deng, L.Q. Zhang, B. Liu, R. Xu, X.D. Zhang, Sonocatalytic degradation of azo fuchsine in the presence of the Co-doped and $\mathrm{Cr}$-doped mixed crystal $\mathrm{TiO}_{2}$ powders and comparison of their sonocatalytic activities, J. Hazard. Mater. 170 (2009) 398-404.

[17] Y.L. Pang, A.Z. Abdullah, S. Bhatia, Effect of annealing temperature on the characteristics, sonocatalytic activity and reusability of nanotubes $\mathrm{TiO}_{2}$ in the degradation of Rhodamine B, Appl. Catal. B 100 (2010) $393-402$.

[18] Y. Zhai, Y. Li, J. Wang, L.N Yin, Y.M. Kong, G.X. Han, P. Fan, Effective sonocatalytic degradation of organic dyes by using $\mathrm{Er}^{3+}: \mathrm{YAlO}_{3} / \mathrm{TiO}_{2}-\mathrm{SnO}_{2}$ under ultrasonic irradiation, J. Mol. Catal. A 366 (2013) 282-287.

[19] S.G. Li, C.S. Wei, J. Wang, L. Zhang, Y. Li, B.X. Wang, Sonocatalytic activity of Yb, B, Ga-codoped $\mathrm{Er}^{3+}: \mathrm{Y}_{3} \mathrm{Al}_{5} \mathrm{O}_{12} / \mathrm{TiO}_{2}$ in degradation of organic dyes, Mater. Sci. Semicond. Process. 26 (2014) 438-447.

[20] A.Z. Abdullah, P.Y. Ling, Heat treatment effects on the characteristics and sonocatalytic performance of $\mathrm{TiO}_{2}$ in the degradation of organic dyes in aqueous solution, J. Hazard. Mater. 173 (2010) 159-167.

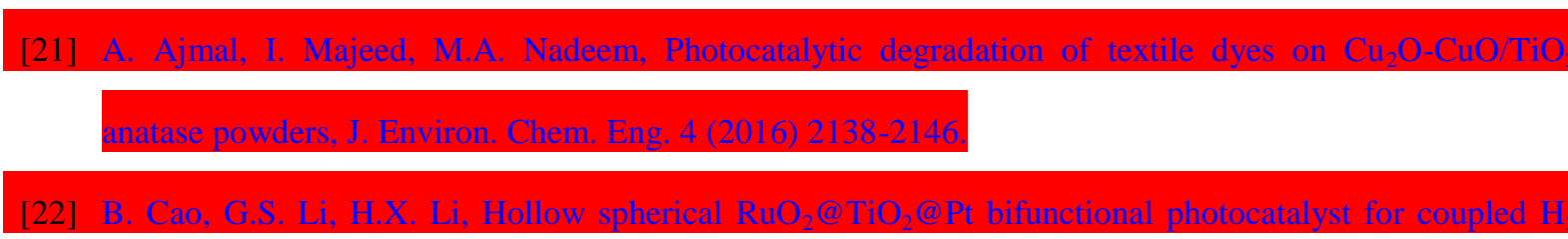

production and pollutant degradation, Appl. Catal. B 194 (2016) $42-49$

[23] M.H. Li, S.J. Zhang, L. Lv, M.S. Wang, W.M. Zhang, B.C. Pan, A thermally stable mesoporous $\mathrm{ZrO}_{2}-\mathrm{CeO}_{2}-\mathrm{TiO}_{2}$ visible light photocatalyst, Chem. Eng. J. 229 (2013) 118-125.

[24] H. Salavati, N. Tavakkoli, M. Hosseinpoor, Preparation and characterization of polyphosphotungstate/ $\mathrm{ZrO}_{2}$ nanocomposite and their sonocatalytic and photocatalytic activity under UV light illumination, Ultrason. Sonochem. 19 (2012) 546-553.

[25] P. Bansal, G.R. Chaudhary, S.K. Mehta, Comparative study of catalytic activity of $\mathrm{ZrO}_{2}$ nanoparticles for sonocatalytic and photocatalytic degradation of cationic and anionic dyes, Chem. Eng. J. 280 (2015) 475-485.

[26] N. Sapawe, A.A. Jalil, S. Triwahyono, One-pot electro-synthesis of $\mathrm{ZrO}_{2}-\mathrm{ZnO} / \mathrm{HY}$ nanocomposite for photocatalytic decolorization of various dye-contaminants, Chem. Eng. J. 225 (2013) 254-265.

[27] H. Sudrajat, S. Babel, H. Sakai, S. Takizawa, Rapid enhanced photocatalytic degradation of dyes using novel N-doped $\mathrm{ZrO}_{2}$, J. Environ. Manage. 165 (2016) 224-234. 
[28] T. Sreethawong, S. Ngamsinlapasathian, S. Yoshikawa, Synthesis of crystalline mesoporous-assembled $\mathrm{ZrO}_{2}$ nanoparticles via a facile surfactant-aided sol-gel process and their photocatalytic dye degradation activity, Chem. Eng. J. 228 (2013) 256-262.

[29] R. Sasikala, A.R. Shirole, V. Sudarsan, K.G. Girija, R. Rao, C. Sudakar, S.R. Bharadwaj, Improved photocatalytic activity of indium doped cadmium sulfide dispersed on zirconia, J. Mater. Chem. 21(2011) 16566-16573.

[30] M.G. Alalm, S. Ookawara, D. Fukushi, A. Sato, A. Tawfik, Improved $\mathrm{WO}_{3}$ photocatalytic efficiency using $\mathrm{ZrO}_{2}$ and $\mathrm{Ru}$ for the degradation of carbofuran and ampicillin, J. Hazard. Mater. 302 (2016) 225-231.

[31] P. Yang, S.S. Yang, Z.N. Shi, F. Tao, X.L. Guo, R.X. Zhou, Accelerating effect of $\mathrm{ZrO}_{2}$ doping on catalytic performance and thermal stability of $\mathrm{CeO}_{2}-\mathrm{CrO}_{\mathrm{x}}$ mixed oxide for 1,2-dichloroethane elimination, Chem. Eng. J. 285 (2016) 544-553.

[32] S.M. Zhang, L. Su, L. Liu, G.Z. Fang, Degradation on hydrogenolysis of soda lignin using $\mathrm{CuO} / \mathrm{SO}_{4}{ }^{2-} / \mathrm{ZrO}_{2}$ as catalyst, Ind. Crop. Prod 77 (2015) 451-457.

[33] J. Wang, Y.H. Lv, L.Q. Zhang, B. Liu, R.Z. Jiang, G.X. Han, R. Xu, X.D. Zhang, Sonocatalytic degradation of organic dyes and comparison of catalytic activities of $\mathrm{CeO}_{2} / \mathrm{TiO}_{2}, \mathrm{SnO}_{2} / \mathrm{TiO}_{2}$ and $\mathrm{ZrO}_{2} / \mathrm{TiO}_{2}$ composites under ultrasonic irradiation, Ultrason. Sonochem. 17 (2010) 642-648.

[34] Y.L. Pang, S. Lim, H.C. Ong, W.T. Chong, Synthesis, characteristics and sonocatalytic activities of calcined $\gamma-\mathrm{Fe}_{2} \mathrm{O}_{3}$ and $\mathrm{TiO}_{2}$ nanotubes $/ \gamma-\mathrm{Fe}_{2} \mathrm{O}_{3}$ magnetic catalysts in the degradation of Orange $\mathrm{G}$, Ultrason. Sonochem. 29 (2016) 317-327.

[35] L. Zhu, Z.D. Meng, C.Y. Park, T. Ghosh, W.C. Oh, Characterization and relative sonocatalytic efficiencies of a new MWCNT and CdS modified $\mathrm{TiO}_{2}$ catalysts and their application in the sonocatalytic degradation of rhodamine B, Ultrason. Sonochem. 20 (2013) 478-484.

[36] T. Ghosh, K. Ullah, V. Nikam, C.Y. Park, Z.D. Meng, W.C. Oh, The characteristic study and sonocatalytic performance of CdSe-graphene as catalyst in the degradation of azo dyes in aqueous solution under dark conditions, Ultrason. Sonochem. 20 (2013) 768-776.

[37] L.M. Song, C. Chen, S.J. Zhang, Sonocatalytic performance of $\mathrm{Tb}_{7} \mathrm{O}_{12} / \mathrm{TiO}_{2}$ composite under ultrasonic irradiation, Ultrason. Sonochem. 18 (2011) 713-717.

[38] A.A. Dougna, B. Gombert, T. Kodom, G.D Boundjou, S. Boukari, N. Leitner, L.M. Bawa, Photocatalytic removal of phenol using titanium dioxide deposited on different substrates: Effect of inorganic oxidants, J. 
Photoch. Photobio. A 305 (2015) 67-77.

[39] H. Kim, H.Y. Yoo, S. Hong, S. Lee, S. Lee, B.S. Park, H. Park, C. Lee, J. Lee, Effects of inorganic oxidants on kinetics and mechanisms of $\mathrm{WO}_{3}$-mediated photocatalytic degradation, Appl. Catal. B 162 (2015) 515-523.

[40] A. Khataee, R. Soltani, A. Karimi, S.W. Joo, Sonocatalytic degradation of a textile dye over Gd-doped $\mathrm{ZnO}$ nanoparticles synthesized through sonochemical process, Ultrason. Sonochem. 23 (2015) 219-230.

[41] J. Wang, Z. Jiang, Z.H. Zhang, Y.P. Xie, Y.H. Lv, J. Li, Y.Q. Deng, X.D. Zhang, Study on inorganic oxidants assisted sonocatalytic degradation of Acid Red B in presence of nano-sized ZnO powder, Sep. Purif. Technol. 67 (2009) 38-43.

[42] H.B. Zhang, C.S. Wei, Y.Y. Huang, J. Wang, Preparation of cube micrometer potassium niobate $\left(\mathrm{KNbO}_{3}\right)$ by hydrothermal method and sonocatalytic degradation of organic dye, Ultrason. Sonochem. 30 (2016) 61-69.

[43] J. Wang, S.Y. Zhou, J. Wang, S.G. Li, P. Fan, Improvement of sonocatalytic activity of $\mathrm{TiO}_{2}$ by using Yb, $\mathrm{N}$ and F-doped $\mathrm{Er}^{3+}: \mathrm{Y}_{3} \mathrm{Al}_{5} \mathrm{O}_{12}$ for degradation of organic dyes, Ultrason. Sonochem. 21 (2014) 84-92.

[44] K.C. Soni, S.C. Shekar, B. Singh, T. Gopi, Catalytic activity of $\mathrm{Fe} / \mathrm{ZrO}_{2}$ nanoparticles for dimethyl sulfide oxidation. J. Colloid. Interf. Sci. 446 (2015) 226-236.

[45] Z.D. Meng, L. Zhu, J.G Choi, C.Y. Park, W.C. Oh, Sonocatalytic degradation of Rhodamine B in the presence of $\mathrm{C}_{60}$ and $\mathrm{CdS}$ coupled $\mathrm{TiO}_{2}$ particles, Ultrason. Sonochem. 19 (2012) 143-150.

[46] M. Taguchi, T. Nakane, A. Matsushita, One-pot synthesis of monoclinic $\mathrm{ZrO}_{2}$ nanocrystals unde subcritical hydrothermal conditions, J. Supercrit. Fluid. 85 (2014) 57-61

[47] M. Tan, Q. Liu, N. Zhang, H.Q. Hu, B. Li, X.J. Kang, Characterization of the surface film on Zr-based bulk metallic glass using X-ray photoelectron spectroscopy (XPS) and scanning electron microscopy (SEM), J. Alloy. Compd. 509 (2011) 5926-5930.

[48] H. Eskandarloo, A. Badiei., M.A. Behnajady, G.M. Ziarani, Ultrasonic-assisted degradation of phenazopyridine with a combination of Sm-doped $\mathrm{ZnO}$ nanoparticles and inorganic oxidants, Ultrason. Sonochem. 28 (2016) 169-177.

[49] R.D.C. Soltani, M. Safari, M. Mashayekhi, Sonocatalyzed decolorization of synthetic textile wastewate using sonochemically synthesized MgO nanostructures, Ultrason. Sonochem. 30 (2016) 123-131

[50] H. Eskandarloo, A. Badiei, M.A. Behnajady, A. Tavakoli, G.M. Ziarani, Ultrasonic-assisted synthesis of 
Ce doped cubic-hexagonal $\mathrm{ZnTiO}_{3}$ with highly efficient sonocatalytic activity, Ultrason. Sonochem. 29 (2016) 258-269.

[51] R.D.C. Soltani, M. Safari, Periodate-assisted pulsed sonocatalysis of real textile wastewater in the presence of $\mathrm{MgO}$ nanoparticles: Response surface methodological optimization, Ultrason. Sonochem. 32 (2016) 181-190 


\section{Content of Figures:}

Fig. 1. XRD patterns of the prepared $\mathrm{CdS}(\mathrm{a}), \mathrm{ZrO}_{2}$ (b) and $\mathrm{CdS}-$ coated $\mathrm{ZrO}_{2}$ (c).

Fig. 2. SEM images of the prepared $\mathrm{CdS}$ (a), $\mathrm{ZrO}_{2}$ (b) and $\mathrm{CdS}$-coated $\mathrm{ZrO}_{2}$ (c) and TEM images of the prepared CdS-coated $\mathrm{ZrO}_{2}(\mathrm{~d})$.

Fig. 3. XPS spectra of the prepared CdS-coated $\mathrm{ZrO}_{2}$ as sonocatalyst.

Fig. 4. Gas chromatography of pethidine hydrochloride solutions and comparison of sonocatalytic degradation caused by prepared CdS-coated $\mathrm{ZrO}_{2}$ in the presences of different kinds of inorganic oxidants. (experimental conditions: $10.00 \mathrm{mg} / \mathrm{L}$ pethidine hydrochloride concentration, $1.00 \mathrm{~g} / \mathrm{L} \mathrm{CdS}$-coated $\mathrm{ZrO}_{2}$ addition amount, 135 min ultrasonic irradiation time and $300 \mathrm{~W}$ output power and $40 \mathrm{kHz}$ frequency ultrasonic irradiation.)

Fig. 5. The influence of inorganic oxidant concentration on the sonocatalytic degradation of pethidine hydrochloride caused by prepared $\mathrm{CdS}$-coated $\mathrm{ZrO}_{2}$. (experimental conditions: $10.00 \mathrm{mg} / \mathrm{L}$ pethidine hydrochloride concentration, $1.00 \mathrm{~g} / \mathrm{L}$ CdS-coated $\mathrm{ZrO}_{2}$ addition amount, $135 \mathrm{~min}$ ultrasonic irradiation time and $300 \mathrm{~W}$ output power and $40 \mathrm{kHz}$ frequency ultrasonic irradiation.)

Fig. 6. The influence of ultrasonic irradiation time (a) and the corresponding reaction kinetics (b) on the sonocatalytic degradation of pethidine hydrochloride. (experimental conditions: $10.00 \mathrm{mg} / \mathrm{L}$ pethidine hydrochloride concentration, $1.00 \mathrm{~g} / \mathrm{L}$ CdS-coated $\mathrm{ZrO}_{2}$ addition amount, $10 \mathrm{mmol} / \mathrm{L}$ inorganic oxidant concentration and $300 \mathrm{~W}$ output power and $40 \mathrm{kHz}$ frequency ultrasonic irradiation.)

Fig. 7. Sonocatalystic degradation principle of pethidine hydrochloride in the presence of CdS-coated $\mathrm{ZrO}_{2}$ composite under ultrasonic irradiation. 


\section{Figures:}
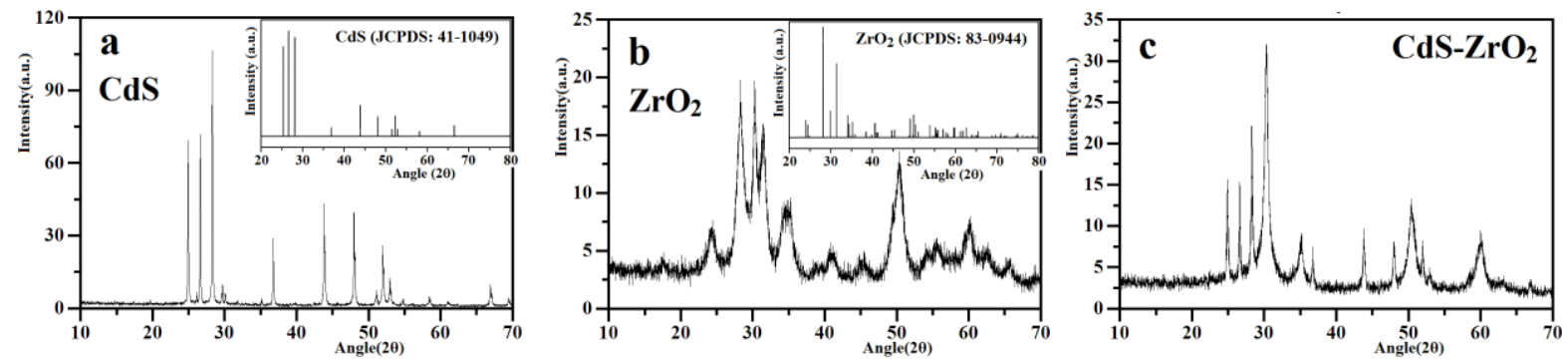

iig. 1. XRD patterns of the prepared $\mathrm{CdS}$ (a), $\mathrm{ZrO}_{2}$ (b) and CdS-coated $\mathrm{ZrO}_{2}$ (c). 


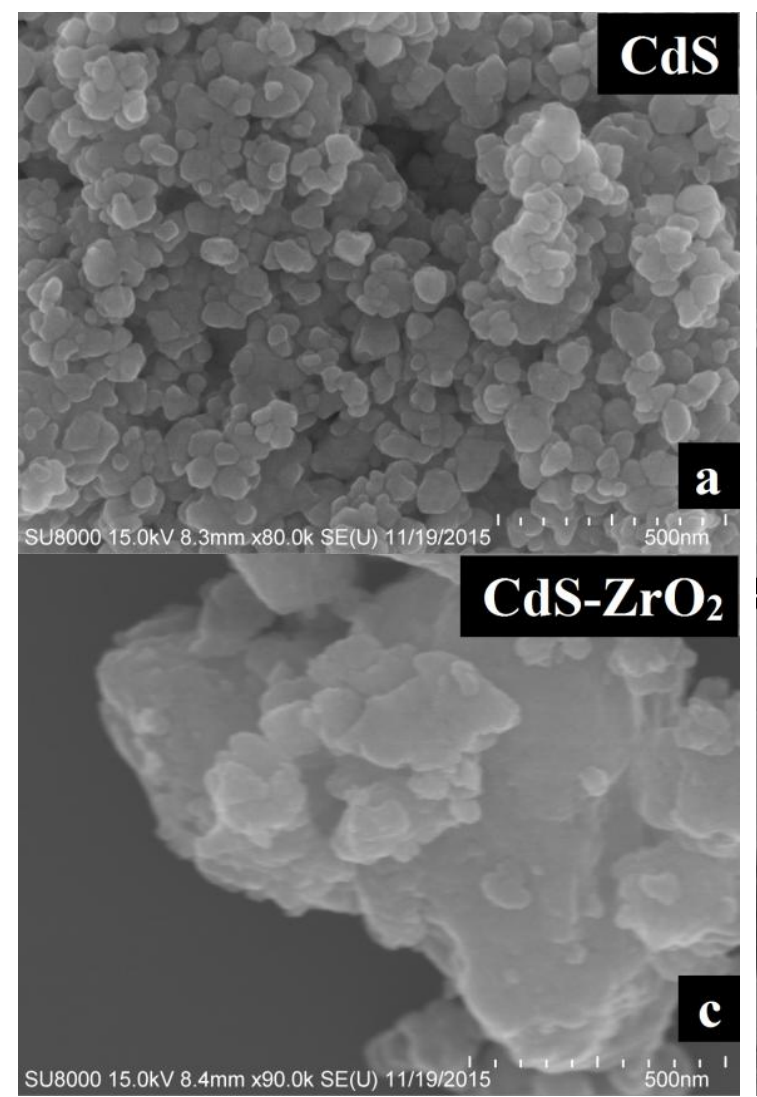

Fig. 2. SEM images of the prepared $\mathrm{CdS}$ (a), $\mathrm{ZrO}_{2}$ (b) and
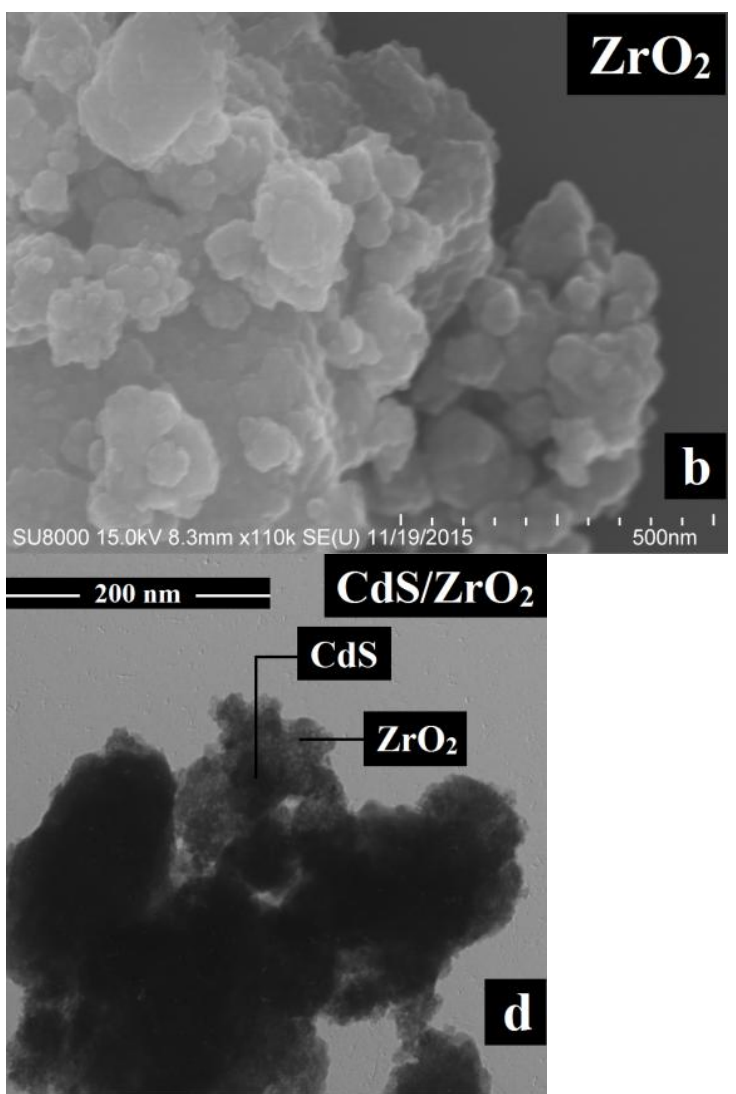

d

CdS-coated $\mathrm{ZrO}_{2}(\mathrm{~d})$. 

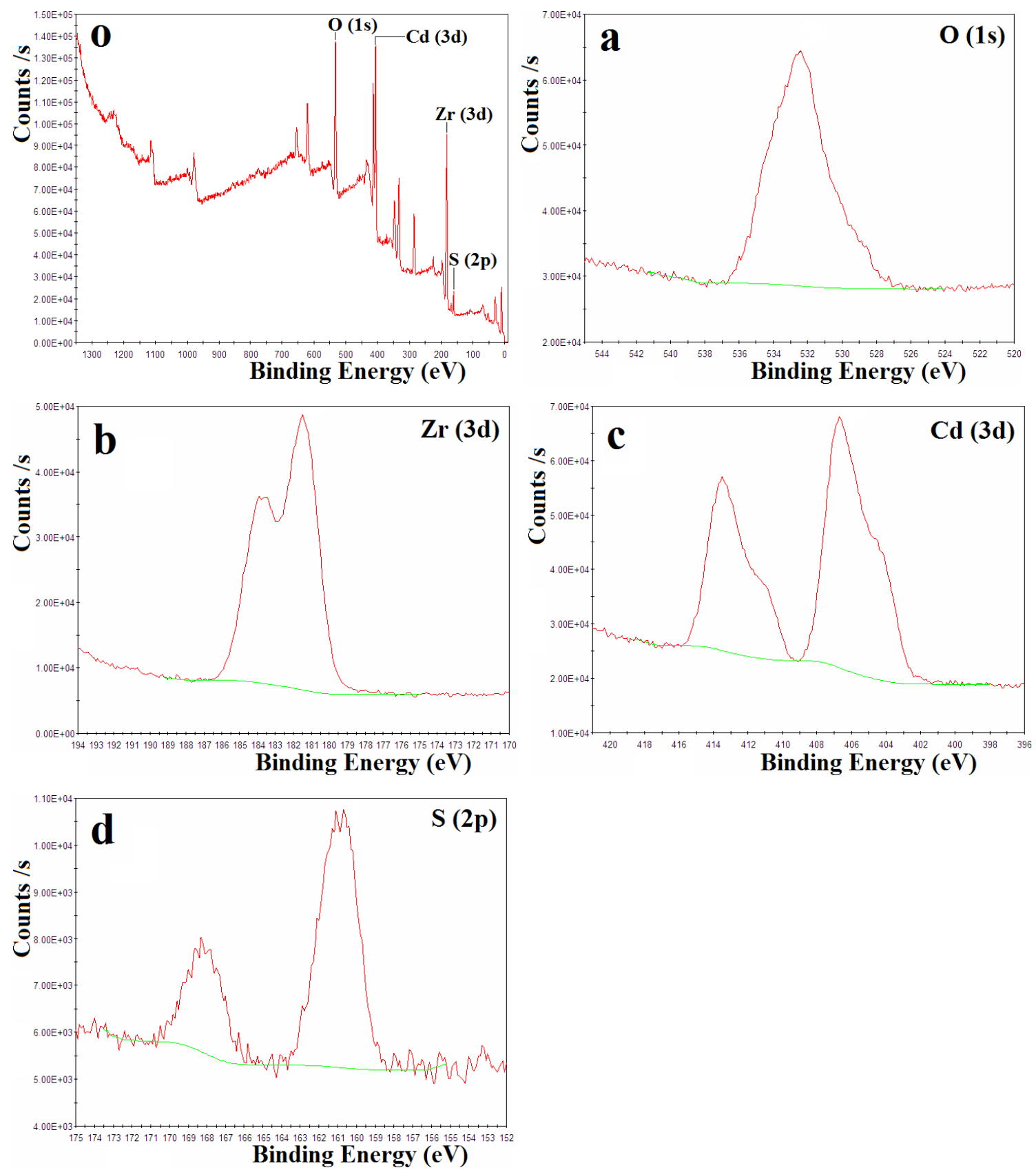

Fig. 3. XPS spectra of the prepared $\mathrm{CdS}$-coated $\mathrm{ZrO}$ as sonocatalyst. 


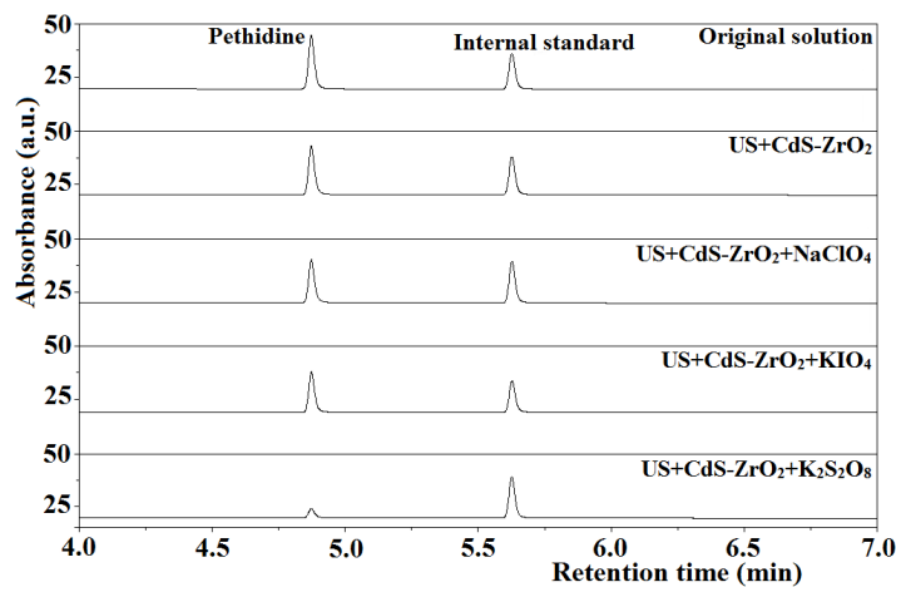

Fig. 4. Gas chromatography of pethidine hydrochloride solutions and comparison of sonocatalytic degradation caused by prepared $\mathrm{CdS}$-coated $\mathrm{ZrO}_{2}$ in the presences of different kinds of inorganic oxidants. (experimental conditions: $10.00 \mathrm{mg} / \mathrm{L}$ pethidine hydrochloride concentration, $1.00 \mathrm{~g} / \mathrm{L}$ CdS-coated $\mathrm{ZrO}_{2}$ addition amount, 135 min ultrasonic irradiation time and $300 \mathrm{~W}$ output power and $40 \mathrm{kHz}$ frequency ultrasonic irradiation.) 


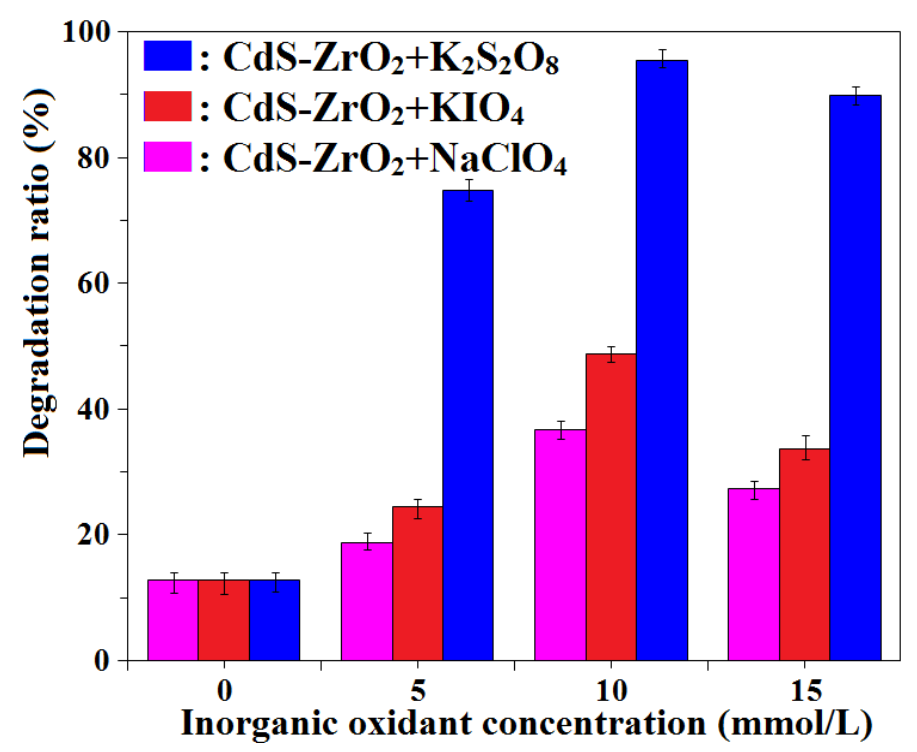

Fig. 5. The influence of inorganic oxidant concentration on the sonocatalytic degradation of pethidine hydrochloride caused by prepared CdS-coated $\mathrm{ZrO}_{2}$. (experimental conditions: $10.00 \mathrm{mg} / \mathrm{L}$ pethidine hydrochloride concentration, $1.00 \mathrm{~g} / \mathrm{L}$ CdS-coated $\mathrm{ZrO}_{2}$ addition amount, 135 min ultrasonic irradiation time and $300 \mathrm{~W}$ output power and $40 \mathrm{kHz}$ frequency ultrasonic irradiation.) 

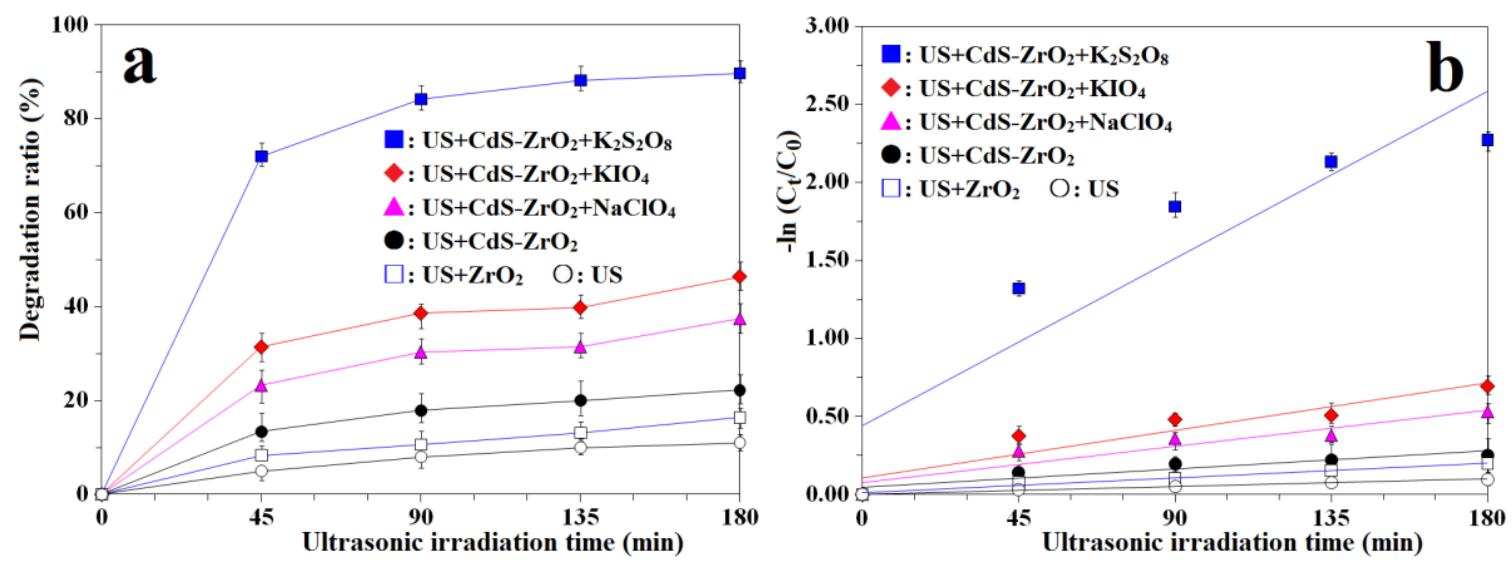

Fig. 6. The influence of ultrasonic irradiation time (a) and the corresponding reaction kinetics (b) on the sonocatalytic degradation of pethidine hydrochloride. (experimental conditions: $10.00 \mathrm{mg} / \mathrm{L}$ pethidine hydrochloride concentration, $1.00 \mathrm{~g} / \mathrm{L}$ sonocatalyst addition amount, $10 \mathrm{mmol} / \mathrm{L}$ inorganic oxidant concentration and $300 \mathrm{~W}$ output power and $40 \mathrm{kHz}$ frequency ultrasonic irradiation.) 


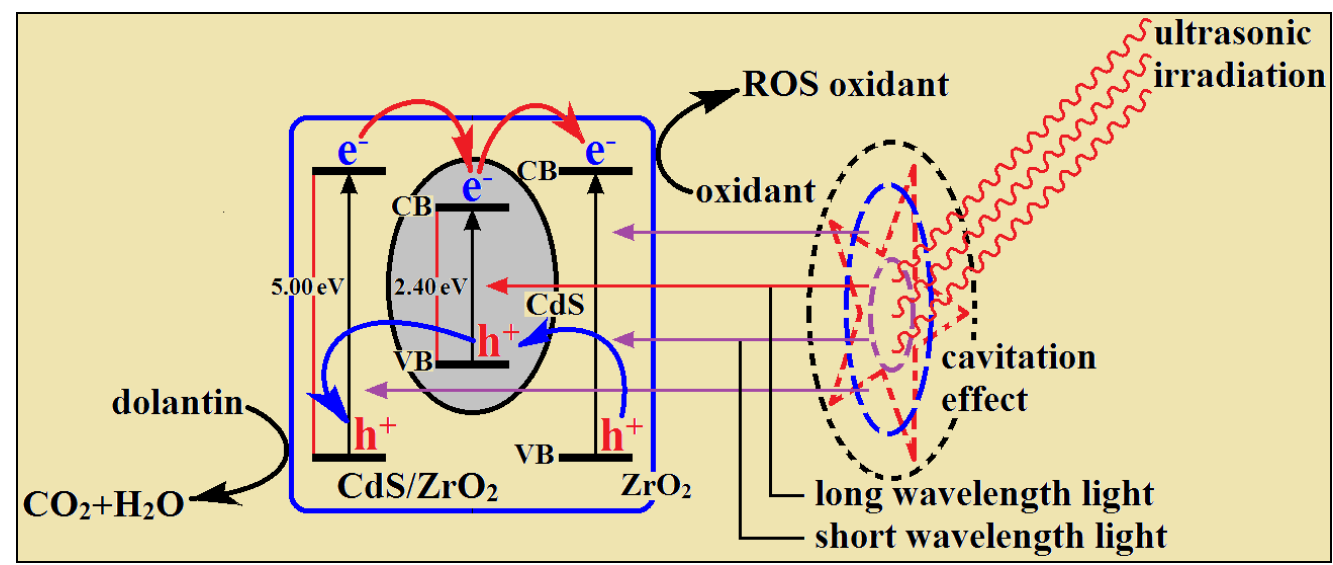

Fig. 7. Sonocatalystic degradation principle of pethidine hydrochloride in the presence of composite under ultrasonic irradiation. 
1、Sema Erdemoğlu: sema.erdemoglu@inonu.edu.t

2、Abdul Aziz Abdul Raman: azizraman@um.edu.my

3、Mohammad Taghi Taghizadeh: mttaghizadeh@ tabrizu.ac.ir 


\title{
Graphical abstract
}

Separation and Purification Technology 000 (2016) 000-000

\section{Article}

\section{Assisted sonocatalytic degradation of pethidine hydrochloride (dolantin) with some inorganic oxidants caused by}

\section{CdS-coated $\mathrm{ZrO}_{2}$ composite}

\author{
Yingying Huang ${ }^{\text {a }}$, Hongbo Zhang ${ }^{\text {a }}$, Chunsheng Wei ${ }^{\text {a,b }}$, Guanshu Li ${ }^{\text {c }}$, Qiong Wu ${ }^{\text {a }}$, \\ Jun Wang ${ }^{\mathrm{a}, *}$, Youtao Song ${ }^{\mathrm{c}, *}$ \\ ${ }^{a}$ College of Chemistry, Liaoning University, Shenyang 110036, P. R. China \\ ${ }^{\mathrm{b}}$ National Police University of China, Shenyang 110854, P. R. China \\ ${ }^{c}$ College of Environment, Liaoning University, Shenyang 110036, P. R. China
}

$\mathrm{CdS}$ was synthesized via hydrothermal method and $\mathrm{CdS}$-coated $\mathrm{ZrO}_{2}$ composite was synthesized via chemical precipitation method. The sonocatalytic degradation of pethidine hydrochloride (dolantin) in aqueous solution was conducted adopting $\mathrm{CdS}$-coated $\mathrm{ZrO}_{2}$ composite as sonocatalyst with inorganic oxidant assisted. The experimental results showed that some inorganic oxidants can effectively assist the sonocatalytic degradation of pethidine hydrochloride in the presence of $\mathrm{CdS}$-coated $\mathrm{ZrO}_{2}$ composite. The best sonocatalytic degradation ratio $(95.50 \%)$ of pethidine hydrochloride could be obtained when the conditions of $10.00 \mathrm{mmol} / \mathrm{L} \mathrm{K}_{2} \mathrm{~S}_{2} \mathrm{O}_{8}, 1.00 \mathrm{~g} / \mathrm{L}$ prepared $\mathrm{CdS}$-coated $\mathrm{ZrO}_{2}$ composite, 135 min ultrasonic irradiation (40 kHz frequency and $300 \mathrm{~W}$ output power), $100 \mathrm{~mL}$ total volume and $25-28{ }^{\circ} \mathrm{C}$ temperature were adopted.

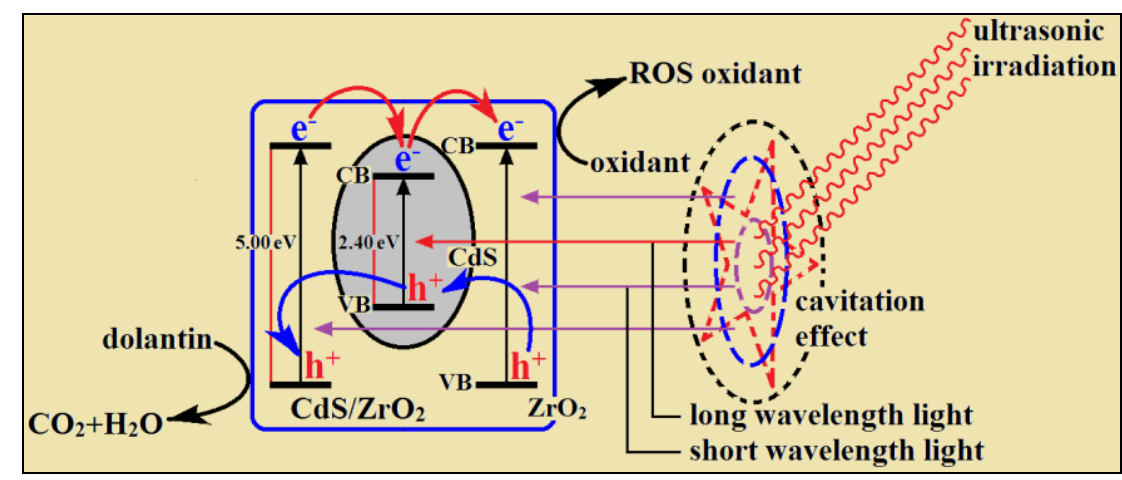

